\title{
Olfactory Neuroblastoma as Acute Postpartum Depression
}

Shimon Dascalu, MD, Benjamin Chayen, MD, Boris Kaplan, MD, and Linda Harel, $M D$

Olfactory neuroblastoma is a rare neuroectodermal malignant tumor. It was first described by Berger et al in $1924,{ }^{1}$ and about 250 cases have since been reported, none of them in the perinatal period. The tumor emerges from the olfactory membrane located in the sinonasal area and anterior cranial fossa. It has a broad histologic spectrum and can be confused with peripheral neuroectodermal tumors. ${ }^{2}$ Early symptoms are intranasal obstruction, epistaxis, and anosmia. ${ }^{3}$ As the tumor grows, it can invade the oral cavity, ${ }^{4}$ the orbits, and the brain. ${ }^{3,5}$ In very rare cases the initial symptom is depression and frontal lobe dysfunction. ${ }^{6}$ We describe a patient with olfactory neuroblastoma in whom the presenting symptom resembled postpartum depression.

\section{Case Report}

The patient, 40 years of age, gravida 3, para 4, first came to our clinic for prepregnancy consultation. All previous pregnancies and deliveries, the most recent 15 years ago, had been uneventful. She had a history of mild hypertension $(140 / 90 \mathrm{mmHg}$ ), which from the 12th week of her last pregnancy was treated with methyldopa $250 \mathrm{mg}$ twice a day.

Results of her primary workup for hypertension performed by her family physician, which included kidney, adrenal, and liver function tests, were normal. In addition, she suffered from chronic sinusitis for which she received homeopathic therapy and antibiotics and nasal spray for acute exacerbations. She was observed by an otolaryngologist before and during pregnancy. Findings on a computerized tomographic (CT) scan of the brain for sinusitis performed within the previous year were normal. She was also mildly obese.

Her intrauterine device was removed at her re-

Submitted, revised 26 January 1998.

Departments of Obstetrics and Gynecology, Ma'ayenei HaYeshua Hospital, Bnei Berak (SD, BC, BK, LH), and Rabin Medical Center, Beilinson Campus, Petah Tiqua, Sackler Faculty of Medicine, Tel Aviv University (SD, BC, BK, LH), Tel Aviv, Israel. Address reprint requests to Boris Kaplan, MD, Department of Obstetrics and Gynecology, Rabin Medical Center, Beilinson Campus, 49100, Petah Tikva, Israel. quest after having been explained the risk of hypertension in pregnancy. She conceived 3 months later. We advised her to attend the high-risk pregnancy clinic. Aside from mild hypertension treated with a daily dose of $100 \mathrm{mg}$ aspirin and $50 \mathrm{mg}$ of atenolol, the pregnancy course was uneventful. Because of suspected macrosomia (estimated fetal weight, $4000 \mathrm{~g}$ ), labor was induced at 38 weeks' gestation by intracervical prostaglandin $\mathrm{E}_{2}$, and a 3920-g baby boy was delivered spontaneously with epidural anesthesia. There were no immediate complications.

Twelve hours later the patient complained of severe headache. Blood pressure and obstetric findings were normal, and the headache was attributed to the epidural anesthesia. Treatment consisted of bed rest, fluid loading, and dipyrone. Twenty-four hours later the patient complained of abdominal pain, became apathetic, lost interest in the newborn, and refused to get out of bed. Catheterization yielded $1800 \mathrm{~mL}$ of urine and led to some improvement in her condition. The next day (48 hours postpartum) she again complained of headache and became apathetic, refusing to get out of bed, or eat; she urinated in bed and did not seem to care.

We suspected postpartum depression. The psychiatrist, however, found no signs of acute psychiatric disease and referred her to a neurosurgeon because of the complaint of headache and her apathy. Asymmetry on preliminary neurologic examination raised suspicion of organic disease. An emergency brain CT scan showed a large space-occupying, fluid-filled left frontal lesion that was exerting extreme pressure on the left lateral ventricle. There was also a lesion showing partial enhancement in the anterior aspect of the brainstem bilaterally, with calcifications and thickening of the basal bone. Another space-occupying lesion was found in the nose invading both orbits medially and invading and filling both ethmoids to the brain stem.

An emergency left temporal craniotomy was performed using general anesthesia. The cystic lesion was drained and $70 \mathrm{cc}$ of yellowish brown 
fluid was aspirated. The tumor at the base of the anterior fossa was removed; it was flaky and vascular and well differentiated from the anterior lobes. A left rhinotomy was performed to remove the tumor from the nose and left orbit. The postoperative period was uneventful with no motoric sequelae or cerebrospinal fluid leakage. A follow-up CT scan showed residual tumor on the right side and in the ethmoidal cells. The histopathologic examination revealed esthesioneuroblastoma.

Magnetic resonance imaging 3 weeks later showed partial recurrence of the frontal cyst and the residual tumor in the ethmoid cells and orbits. A team of neurosurgeons, otolaryngologists, and ophthalmologists performed a second operation. The tumor was completely removed. The postoperative recovery was uneventful, and 7 days after surgery the patient was discharged and referred for radiotherapy.

Three months after radiotherapy the patient's condition was being treated with prophylactic anticonvulsants. At that time she was feeling well and had no signs or symptoms of active disease.

\section{Discussion}

Although it is well known that intracranial tumors occurring in women of reproductive age can produce their first signs and symptoms during pregnancy, to the best of our knowledge, this is the first report of olfactory neuroblastoma occurring in the perinatal period. Pregnancy often masks the existence of the neoplasm, and the diagnosis can easily be missed.' Such symptoms as vomiting, headache, and visual disturbances are attributed by both patient and physician to the pregnancy itself or to preeclampsia. The influence of pregnancy on brain tumors is not completely known. Some authors believe that tumors grow during pregnancy because of the positive water balance as a result of the altered hormonal environment. ${ }^{8}$ Others implicate the engorgement of the blood vessels that feed the tumor. ${ }^{9}$ In our case, too, the brain neoplasm caused symptoms compatible with mild postanesthesia complications.

Olfactory neuroblastoma is a slow-growing tumor, accounting for only 2 to 3 percent of all malignant intracranial tumors. ${ }^{10}$ It occurs in all age groups, but rarely during childhood, with a peak in the second and fifth decades of life (mean age at occurrence, 41 years). ${ }^{11,12}$ There is no true sexual predominance, but some authors report a male-fe- male ratio of 2:1.13 Diagnosis is difficult and requires a high degree of suspicion because the signs and symptoms are nonspecific and the histopathologic findings are often unclear. Ultrastructural examination and identification of specific neural proteins ${ }^{14-16}$ provide confirmation. Clinical symptoms resemble those of other intranasal neoplasms: nasal obstruction, anosmia, and epistaxis. ${ }^{10,17}$ Later, as the tumor invades adjacent structures, the sinuses, orbits, palate, and brain, ${ }^{3-5,18}$ there may be diplopia, ophthalmoplegia, exophthalmus, blurred vision, and blindness. ${ }^{19}$ Our patient had unilateral exophthalmus and blurred vision caused by tumoral pressure on the orbits.

There can also be distant metastases involving the cervical lymph nodes, brain, lungs, bone, and liver, ${ }^{17,20,21}$ and local recurrence appears in about 50 percent of cases. ${ }^{17,22}$ The biologic behavior is unpredictable, ranging from a benign neoplasm to a highly malignant tumor. The tumor is not usually associated with hormone secretion, but in some cases it has been found to be an arginine vasopressin producer causing inappropriate antidiuretic hormone secretion syndrome. ${ }^{4,23}$ In one case olfactory neuroblastoma was found to produce adrenocorticotropic hormone, causing Cushing syndrome. ${ }^{24}$ Classification is based on the extent of tumor invasion, ${ }^{20}$ and the staging system proposed by Kadish et al ${ }^{21}$ provides a reference point for therapy and prognosis.

Olfactory neuroblastoma has been traditionally treated by radical surgery. Several authors have reported that the tumor is radiosensitive ${ }^{21}$ and can also be treated successfully by chemotherapeutic agents. 25,26 The best treatment today seems to be oral surgery and neurosurgery combined with radiation and chemotherapy. Our patient underwent surgery twice for complete tumor removal and subsequent radiation therapy with good results at 3 months' follow-up. We cannot yet determine the precise prognosis.

The 5-year survival rate ranges from 20 percent to 71 percent ${ }^{17,20,27}$ for olfactory neuroblastoma. Analysis of the various studies indicates no relation between the type of treatment and survival rate. ${ }^{20,21}$ Apparently the biologic behavior of the tumor and the prognosis are determined not only by the extent of spread at the time of diagnosis and beginning of treatment but also by the histologic type and substance of secretions. Some of the latter still require further investigation. 


\section{References}

1. Berger L, Luc G, Richard D. L'esthesioneuroepitheliome olfactif. Bull Assoc Franc Etude Cancer 1924; 13:410.

2. Nelson RS, Perlman EJ, Askin FB. Is esthesioneuroblastoma a peripheral neuroectodermal tumor. Hum Pathol 1995;26:639-41.

3. Mills SE, Frierson HF Jr. Olfactory neuroblastoma: a clinicopathologic study of 21 cases. Am J Surg Pathol 1985;9:317-27.

4. Myers SL, Hardy DA, Wiebe CB, Shiffman J. Olfactory neuroblastoma invading the oral cavity in a patient with inappropriate antidiuretic hormone secretion. Oral Surg Oral Med Oral Pathol 1994;77: 645-50.

5. Batsakis JG. Tumors of the head and neck. 2nd ed. Baltimore: Williams \& Wilkins, 1979:338-49.

6. Griffith JP. Esthesioneuroblastoma: an unusual cause of frontal lobe dysfunction. W V Med J 1995;91: 142-3.

7. Chaudhuri P, Wallenburg HC. Brain tumors and pregnancy. Presentation of a case and review of the literature. Eur J Obstet Gynecol Reprod Biol 1980; 11:109-14.

8. Weyland RD, McCarthyu CS, Wilson RB. The effect of pregnancy on intracranial meningiomas occurring about the optic chiasma. Surg Clin North Am 1951;31:122.

9. King AB. Neurological conditions occurring as complications of pregnancy. Arch Neurol Psychiatry 1950;63:611.

10. Suen JY, Myers EN, editors. Cancer of the Head and Neck. New York: Churchill Livingstone, 1981: 673-7.

11. Tamada A, Makimoto K, Okawa M, Hirono Y, Yambe $\mathrm{H}$. Olfactory neuroblastoma: presentation of a case and review of the Japanese literature. Laryngoscope 1984;94:252-6.

12. Elkon D, Hightower SI, Lim ML, Cantrell RW, Constable WC. Esthesioneuroblastoma. Cancer 1979;44:1087-94.

13. Bailey BJ, Barton S. Olfactory neuroblastoma: management and prognosis. Arch Otolaryngol 1975;101: 1-5.

14. Charters AR, Kobayashi M, Butcher SP. Immunochemical analysis of FK506 binding proteins in neu- ronal cell lines and rat brain. Biochem Soc Trans 1994:22:411.

15. Reinhard E, Suidan HS, Pavlik A, Monard D. Gliaderived nexin/protease nexin-1 is expressed by a subset of neurons in the rat brain. J Neurosci Res 1994; 37:256-70.

16. Yang Y, Zeng Q. [Olfactory neuroblastoma: a histopathological ultrastructural and immunohistochemical study of 11 cases.] Chung Hua Ping Li Hsueh Tsa Chih 1995;24(1):39-42.

17. Olsen KD, De Santo LW. Olfactory neuroblastoma. Biologic and clinical behavior. Arch Otolaryngol 1983;109:797-802.

18. Russell DS, Rubinstein LJ. Pathology of tumors of the nervous system. 4th ed. Edinburgh; Arnold, 1977:412-3.

19. Rakes SM, Yeatts RP, Campbell RJ. Ophthalmic manifestations of esthesioneuroblastoma. Ophthalmology 1985;92:1749-53.

20. Anavi Y, Bahar M, Ben Bassat M. Olfactory neuroblastoma: report of a case and review of the literature. J Oral Maxillofac Surg 1989;47:514-7.

21. Kadish S, Goodman M, Wang CC. Olfactory neuroblastoma. A clinical analysis of 17 cases. Cancer 1976;37:1571-6.

22. Appelblatt NH, McClatchey KD. Olfactory neuroblastoma: a retrospective clinicopathologic study. Head Neck Surg 1982 5:108-13.

23. al Ahwal M, Jha N, Nabholtz JM, Hugh J, Birchall I, Nguyen GK. Olfactory neuroblastoma: report of a case associated with inappropriate antidiuretic hormone secretion. J Otolaryngol 1994;23:437-9.

24. Arnesen MA, Scheithauer BW, Freeman S. Cushing's syndrome secondary to olfactory neuroblastoma. Ultrastruct Pathol 1994;18(1-2):61-8.

25. Wade PM Jr, Smith RE, Johns ME. Response of esthesioneuroblastoma to chemotherapy. Report of five cases and review of the literature. Cancer 1984; 53:1036-41.

26. Kempf HG, Becker G, Weber BP, Ruck P. [Diagnosis and therapy of olfactory neuroblastoma.] HNO 1994;42:422-8.

27. Skolnic EM, Massari FS, Tenta LT. Olfactory neuroepithelioma. Review of the world literature and presentation of two cases. Arch Otolaryngol 1966; 84:644-53. 